\title{
Comparison of robotic and open partial nephrectomy: Single-surgeon matched cohort study
}

\author{
Jong Jin Oh, MD; Seoksoo Byun, MD; Sung Kyu Hong, MD; Chang Wook Jeong, MD; Sang Eun Lee, MD
}

Department of Urology, Seoul National University Bundang Hospital, Seongnam, Korea

Cite as: Can Urol Assoc J 2014;8(7-8):e471-5. http://dx.doi.org/10.5489/cuaj.1679 Published online July 18, 2014.

\section{Abstract}

Introduction: We present comparative outcomes among matched patients who underwent robotic partial nephrectomy (RPN) or open partial nephrectomy (OPN) by a single surgeon at a single institution.

Methods: We reviewed the medical records of 200 patients who underwent RPN ( $n=100)$ or OPN $(n=100)$ between May 2003 and May 2013. The patients who underwent RPN were matched for age, gender, body mass index (BMI), American Society of Anesthesiologists (ASA) score, as well as tumour size, side and location. Perioperative outcomes were compared.

Results: There was no significant difference between the 2 cohorts with respect to patient age, BMI, ASA score, preoperative glomerular filtration rate, tumour size and the R.E.N.A.L. nephrometry score. The mean operative time was longer in the RPN group, but there were no significant differences with respect to warm ischemic time and postoperative renal function. The length of hospitalization and use of postoperative analgesics (ketoprofen) were more favourable in the RPN cohort. There was no significant difference in the mean estimated blood loss, transfusion rate, or complications between the cohorts.

Conclusions: Considering the perioperative and postoperative parameters, RPN is a viable option as a nephron-sparing surgical procedure for small renal masses that yields outcomes comparable to those achieved with OPN. Despite matched cohort analysis among patients who underwent PN by a single surgeon, there may be inherent selection bias; therefore future prospective trials are needed.

\section{Introduction}

Radical nephrectomy $(\mathrm{RN})$ has been considered the gold standard for managing small renal masses (SRMs). ${ }^{1}$ With the improvement of surgical techniques, partial nephrec- tomy (PN) has now become the norm for the management of renal tumours smaller than $4 \mathrm{~cm}(\mathrm{~T} 1 \mathrm{a}){ }^{2,3} \mathrm{~A}$ recent series showed a similarity between $\mathrm{PN}$ and $\mathrm{RN}$ for oncological control and demonstrated the superiority of PN for preserving renal function, preventing chronic renal disease along with associated cardiovascular morbidity and mortality, and improving overall survival rates. ${ }^{4,5}$

Over the last decade, laparoscopic surgery has become the common technique for many urologic procedures. The main advantages of minimally invasive surgery are lower blood loss and transfusion rates, reduced postoperative pain and scarring, faster recovery from surgery, and a shorter length of hospitalization. In contrast, laparoscopic partial nephrectomy (LPN) is considered a technically challenging procedure that requires considerable skill and expertise, such as intracorporeal suturing, combined with the necessity to minimize ischemic times. ${ }^{6}$

Robot-assisted partial nephrectomy (RPN) may help overcome the technical challenges of LPN and offers an easier transition to minimally invasive PN. ${ }^{7} \mathrm{RPN}$ is suitable for intracorporeal suturing with the use of an endo-wrist instrument. ${ }^{8}$ To date, numerous preliminary studies on RPN have shown that this technique is comparable to LPN. ${ }^{9}$ Although one recent report on the outcomes of RPN compared with OPN has been promising, ${ }^{10}$ there are almost no studies that have compared RPN with OPN. We present a single-surgeon comparative study of OPN and RPN in matched patients.

\section{Methods}

Between May 2003 and May 2013, a retrospective cohort study was performed to evaluate perioperative outcomes among patients who underwent RPN and to compare these results with those of a matched cohort of patients who were selected among the OPN database. This study was approved by the Institutional Review Board of Seoul National University Bundang Hospital. 
Oh et al.

A total of 100 consecutive RPN patients were matched with 100 OPN patients who were similar with respect to age, body mass index (BMI), American Society of Anesthesiologists (ASA) score, laterality of the tumour, tumour size, tumour location and preoperative glomerular filtration rate (GFR). We also matched the cohorts according to the R.E.N.A.L. nephrometry scoring system. ${ }^{11}$ We excluded patients with a single kidney, bilateral renal masses, von Hippel-Lindau syndrome or OPN under hypothermia with cold ischemia.

We defined exophytic tumours as those that covered more than $60 \%$ off the natural kidney surface. Endophytic tumours covered less than $40 \%$ of the surface of the kidney, and mesophytic tumours covered $40 \%$ to $60 \%$ of the natural border of the kidney. Hilar lesions were defined by localization within $5 \mathrm{~mm}$ of the renal hilar structures regardless of their surface characteristics. ${ }^{12}$ The total R.E.N.A.L. nephrometry score was categorized as low (4-6 points), moderate (7-9), or high (10-12) complexity. ${ }^{11}$ The specimens obtained from PNs were evaluated for pathologic tumour size, histologic subtype, Fuhrman nuclear grade, and pathologic tumour-node-metastasis stage according to the 7 th edition of the American Joint Committee on Cancer Cancer (AJCC) Staging Manual. ${ }^{13}$

Follow-up abdominal imaging studies, such as computed tomography $(\mathrm{CT})$, were performed every 6 to 12 months after non-sparing surgery to assess recurrence. Functional renal outcomes were assessed by comparing preoperative and postoperative GFR and creatinine levels. A 3-arm technique was used during RPN, and 2 additional assistant ports were placed. Port location was tailored to the location of the mass and renal hilum. All of the hilar control procedures during RPN and OPN were performed under warm ischemia. In cases of RPN, hilar control was achieved by clamping the renal artery. In some hilar tumours, the renal veins were also controlled with bulldog clamps. Similar hilar control was achieved in OPN cases. Most renal reconstruction during RPN consisted of a 2-layer repair. The first part of the repair involved intraparenchymal suturing to close the collecting system and to achieve hemostasis with the use of continuous 3-0 polyglactin and Lapra-Tys sutures (Ethicon, Somerville, $\mathrm{NJ}$ ). The second part of the repair involved parenchymal suturing with the use of 1-0 polyglactin and a sliding-knot technique. When the expected ischemia time was $\geq 30 \mathrm{~min}-$ utes, early unclamping was performed after intraparenchymal suturing. ${ }^{14}$ Supplementary ties over a Surgicel (Ethicon, Somerville, NJ) or TachoComb (NYCOMED, Linz, Austria) bolster were created using remnant 1-0 sutures. A topical hemostatic agent, Tissel (Baxter Corp, Deerfield, IL), was applied over the bolster and at the base of the resection bed. Similar renal reconstruction was performed in OPN cases.

All data analyses were performed using the Statistical Package for the Social Sciences 17.0 software (SPSS Inc, Chicago, IL). We tested the distribution of clinicopathologic parameters using chi-square and Student's t tests. We compared the complications and renal functional outcomes after nephrectomies according to surgical methods. Complications were stratifided by Clavein Dindo classficiation. ${ }^{15}$ All $p$ values were two-sided and $<0.05$ was considered significant.

\section{Results}

A total of 100 consecutive patients who underwent RPN were reviewed and matched to a contemporary cohort of 100 patients who underwent OPN by the same surgeon. Demographic data are summarized in Table 1. There was no significant difference between the 2 cohorts with respect to age, gender, BMI, ASA score, tumour laterality, tumour size, tumour location, R.E.N.A.L. nephrometry score or preoperative eGFR.

Table 2 shows the perioperative outcomes for both groups. The mean operative time was longer in the RPN group (182 vs. 138 min, $p<0.001$ ), but the mean warm ischemia time (WIT) was similar between the RPN and OPN cohorts (21.86 vs. $21.18 \mathrm{~min}, p=0.734)$. There were no significant differences between the groups (RPN vs. OPN) in terms of the estimated blood loss (EBL) $(212 \mathrm{vs} .230 \mathrm{~mL}$, $p=0.545)$ and transfusion rate $(6.0 \%$ vs. $4.0 \%, p=0.661)$.

\begin{tabular}{|c|c|c|c|}
\hline Characteristics & OPN $(n=100)$ & RPN (n=100) & $p$ value \\
\hline Age, years & $54.59 \pm 13.40$ & $54.27 \pm 11.52$ & 0.896 \\
\hline Sex & & & 0.835 \\
\hline Male & $69(69.0 \%)$ & $70(70.0 \%)$ & \\
\hline Female & $31(31.0 \%)$ & $30(30.0 \%)$ & \\
\hline Body mass index, $\mathrm{kg} / \mathrm{m}^{2}$ & $25.14 \pm 2.73$ & $25.48 \pm 3.47$ & 0.161 \\
\hline Mean ASA score & 1.6 & 1.5 & 0.280 \\
\hline Tumour laterality & & & 0.847 \\
\hline Right & $52(52.0 \%)$ & $46(46.0 \%)$ & \\
\hline Left & $48(48.0 \%)$ & $54(54.0 \%)$ & \\
\hline $\begin{array}{l}\text { Tumour size, } \mathrm{cm} \\
\text { (range) }\end{array}$ & $\begin{array}{l}2.59 \pm 1.35 \\
(0.80-6.20)\end{array}$ & $\begin{array}{l}2.52 \pm 1.26 \\
(0.90-6.00)\end{array}$ & 0.763 \\
\hline Tumour location & & & 0.437 \\
\hline Exophytic & $26(26.0 \%)$ & $31(31.0 \%)$ & \\
\hline Mesophytic & $23(23.0 \%)$ & $27(27.0 \%)$ & \\
\hline Endophytic & $30(30.0 \%)$ & $27(27.0 \%)$ & \\
\hline Hilar & $21(21.0 \%)$ & $15(15.0 \%)$ & \\
\hline $\begin{array}{l}\text { Median R.E.N.A.L. } \\
\text { nephrometry score (IQR) }\end{array}$ & $7(6-9)$ & $7(6-9)$ & 0.883 \\
\hline Low group & $39(39.0)$ & $40(40.0)$ & \\
\hline Moderate group & $47(47.0)$ & $48(48.0)$ & \\
\hline High group & $14(14.0)$ & $12(12.0)$ & \\
\hline Preopertive $\mathrm{Cr}$, mg/dL & $1.11 \pm 0.37$ & $1.04 \pm 0.22$ & 0.085 \\
\hline Preopertive GFR, $\mathrm{mL} / \mathrm{min}$ & $76.21 \pm 20.95$ & $78.18 \pm 18.42$ & 0.530 \\
\hline \multicolumn{4}{|c|}{$\begin{array}{l}\text { OPN: open partial nephrectomy; RPN: robotic partial nephrectomy; ASA: American Society } \\
\text { of Anesthesiologists; Cr: creatinine; GFR: glomerular filtration rate; IQR: interquartile range. } \\
\text { The total RENAL nephrometry score was categorized as low (4-6 points), moderate (7-9), or } \\
\text { high (10-12) complexity. }\end{array}$} \\
\hline
\end{tabular}


Table 2. Perioperative outcomes

\begin{tabular}{lccc}
\hline Characteristics & OPN $(\mathbf{n}=100)$ & RPN $(\mathbf{n}=100)$ & $p$ value \\
\hline Operative time (min) & $138.79 \pm 40.29$ & $182.89 \pm 83.98$ & $<0.001$ \\
Warm ischemic time & $21.18 \pm 11.29$ & $21.86 \pm 9.25$ & 0.734 \\
(min) (range) & $(6-60)$ & $(6-55)$ & \\
EBL (mL) & $230.74 \pm$ & $212.04 \pm$ & 0.545 \\
Transfusion (\%) & 159.33 & 160.76 & 0.661 \\
Hospital stay (d) & $6(6.0)$ & $4(4.0)$ & $<0.001$ \\
$\begin{array}{l}\text { Postoperative } \\
\text { analgesics (ampule) }\end{array}$ & $9.26 \pm 3.22$ & $5.41 \pm 1.84$ & $<.001$ \\
$\begin{array}{l}\text { Intraoperative } \\
\text { complications (\%) }\end{array}$ & $3(3.0)$ & $4(4.0)$ & 0.714 \\
$\begin{array}{l}\text { Postoperative } \\
\text { complications (\%) }\end{array}$ & $8(8.0)$ & $10(10.0)$ & 0.440 \\
$\begin{array}{l}\text { Prolonged ileus } \\
\text { Wound problem }\end{array}$ & $2(2.0)$ & $3(3.0)$ & \\
$\begin{array}{l}\text { Urine leakage } \\
\text { necessary stent } \\
\text { insertion }\end{array}$ & $0(0.0)$ & $2(2.0)$ & \\
$\begin{array}{l}\text { Prolonged bleeding } \\
\text { Prolonged hematuria }\end{array}$ & $2(2.0)$ & $0(0.0)$ & \\
\hline $\begin{array}{l}\text { OPN: open partial nephrectomy; RPN: robotic partial nephrectomy; EBL: estimated blood } \\
\text { loss. }\end{array}$ & $3(3.0)$ & $1(1.0)$ & \\
\hline
\end{tabular}

As expected, the length of hospitalization (5.4 vs. 9.3 days, $p<0.001$ ) and use of postoperative analgesics (ketoprofen, 0.2 vs. 0.9 ampules, $p<0.001$ ) were more favourable in the RPN cohort.

Intraoperative adverse events occurred in 3 OPN patients $(3.0 \%)$ and 4 RPN patients $(4.0 \%)(p=0.714)$. Complications in the OPN group included 3 cases of pleural injury. Complications in the RPN groups included 2 colon, 1 spleen and 1 renal vein injury. The rate of postoperative complications was $8.0 \%$ in the OPN group and $10.0 \%$ in the RPN group $(p=0.440)$. Most complications were classified as Clavien grade I and II. Clavien grade III complications occurred in 3 patients in the OPN group (urine leakage necessitating ureteral stents, prolonged bleeding necessitating angioembolization) and 2 patients in the RPN group (angioembolization for prolonged bleeding). Most complications in the robotic group occurred among the first 20 cases.

In the OPN cohort, pathologic findings demonstrated AJCC stage T1a in $87(87.0 \%)$ patients and stage $\mathrm{T} 1 \mathrm{~b}$ in 8
Table 3. Pathological outcomes

\begin{tabular}{|c|c|c|c|}
\hline Characteristics & OPN $(n=100)$ & RPN (n=100) & $p$ value \\
\hline $\begin{array}{l}\text { Pathologic diagnosis } \\
(\%)\end{array}$ & & & 0.886 \\
\hline Clear cell RCC & $84(84.0)$ & $81(81.0)$ & \\
\hline Papillary RCC & $6(6.0)$ & $7(7.0)$ & \\
\hline Chromophobe RCC & $4(4.0)$ & $6(6.0)$ & \\
\hline Angiomyolipoma & $2(2.0)$ & $3(3.0)$ & \\
\hline Oncocytoma & $4(4.0)$ & $3(3.0)$ & \\
\hline Pathologic stage (\%) & & & 0.197 \\
\hline pT1a/pT1b & $\begin{array}{c}87(87.0) / 8 \\
(8.0)\end{array}$ & $\begin{array}{c}90(90.0) / 8 \\
(8.0)\end{array}$ & \\
\hline pT2/pT3a & $1(1.0) / 5(5.0)$ & $0(0.0) / 2(2.0)$ & \\
\hline \multicolumn{4}{|l|}{$\begin{array}{l}\text { Fuhrman nuclear } \\
\text { grade }\end{array}$} \\
\hline $1 / 2 / 3 / 4$ & $2 / 50 / 43 / 5$ & $0 / 49 / 50 / 1$ & 0.500 \\
\hline $\begin{array}{l}\text { Resection margin } \\
\text { positive (\%) }\end{array}$ & $1(1.0)$ & $0(0.0)$ & 0.315 \\
\hline
\end{tabular}

(8.0\%) patients. In the RPN cohort, pathology was classified as AJCC stage T1a in $90(90.0 \%)$ patients and stage T1b in $8(8.0 \%)$ patients. The histologic type, pathologic stage, and Fuhrman nuclear grade were not significantly different between the groups (Table 3). The number of patients with positive surgical margins was 0 for the RPN group and 1 for the OPN group $(p=0.500)$.

There was no significant difference in postoperative GFR (71.49 vs. $72.29 \mathrm{~mL} / \mathrm{min}, p=0.147$ ) or percent change in GFR (-6.19\% vs. $-7.53 \%, p=0.418)$ between the OPN and RPN cohorts, respectively (Table 4). Postoperative serum creatinine was also similar between OPN and RPN cohorts (1.14 vs. $1.09 \mathrm{mg} / \mathrm{dL}, p=0.085)$. Likewise, there was no significant difference in percent change in creatinine between the OPN and RPN cohorts ( $2.70 \%$ vs. $4.81 \%, p=0.067)$.

\section{Discussion}

PN has become the standard procedure for removing SRMs. ${ }^{3,16}$ The 10-year oncologic control rate in patients undergoing $\mathrm{PN}$ has been comparable to that of those undergoing RN. ${ }^{16}$ Furthermore, for large tumours $>4 \mathrm{~cm}$, elective $\mathrm{PN}$ should be performed at high-volume centres because

\begin{tabular}{|c|c|c|c|}
\hline Characteristics & OPN $(n=100)$ & RPN (n=100) & $p$ value \\
\hline Mean preoperative serum $\mathrm{Cr}(\mathrm{mg} / \mathrm{dL}) \pm \mathrm{SD}$ & $1.11 \pm 0.32$ & $1.04 \pm 0.12$ & 0.085 \\
\hline Mean postoperative serum $\mathrm{Cr}(\mathrm{mg} / \mathrm{dL})$ at 6 months $\pm \mathrm{SD}$ & $1.14 \pm 0.76$ & $1.09 \pm 0.52$ & 0.157 \\
\hline Mean percentage change of serum $\mathrm{Cr}(\%) \pm \mathrm{SD}$ & $2.70 \pm 1.21$ & $4.81 \pm 1.98$ & 0.067 \\
\hline Mean preoperative GFR $\left(\mathrm{mL} / \mathrm{min} / 1.73 \mathrm{~m}^{2}\right) \pm \mathrm{SD}$ & $76.21 \pm 25.83$ & $78.18 \pm 21.72$ & 0.530 \\
\hline Mean postoperative GFR $\left(\mathrm{mL} / \mathrm{min} / 1.73 \mathrm{~m}^{2}\right)$ at 6 months $\pm \mathrm{SD}$ & $71.49 \pm 31.15$ & $72.29 \pm 29.46$ & 0.147 \\
\hline Mean percentage change GFR $(\%) \pm S D$ & $-6.19 \pm 7.32$ & $-7.53 \pm 4.28$ & 0.418 \\
\hline
\end{tabular}


Oh et al.

the oncologic results achieved are equivalent to those seen with RN, with the added advantage of renal functional preservation. ${ }^{17,18}$

Traditionally, open method was standard surgical approach for PN; however, OPN is associated with some morbidity and prolonged convalescence. ${ }^{19}$ Therefore, LPN was developed and refined to minimize the morbidity associated with OPN. ${ }^{20,21}$ Lane and Gill ${ }^{22}$ assessed the 5-year oncologic and renal functional outcomes in 56 patients. They reported no cancer-specific death, and no patients developed postoperative chronic renal insufficiency. Recent large LPN series were comparable to those of open surgery. ${ }^{20,22,23}$ Gill and colleagues ${ }^{20}$ reported equivalent 3-year cancer-specific survival rates of $99.3 \%$ and $99.2 \%$, respectively, compared with the early postoperative outcomes of 771 LPN and 1028 OPN cases. LPN offers comparable disease control but with less pain, superior cosmesis, and a shortened hospital stay. However, LPN is technically more demanding and has a prohibitive learning curve. ${ }^{24}$ Because in situ renal hypothermia during LPN has been largely unsuccessful, the kidney is placed at considerable risk for post-ischemic injury if WIT takes longer than 30 minutes. ${ }^{25,26}$ Even in expert hands, the mean WIT during LPN approaches or exceeds this threshold. ${ }^{20}$ In our LPN series, the mean WIT was close to 30 minutes and the unfavourable complication rate was higher than among the OPN or RPN series. LPN was more difficult in large-sized and high complex tumours; therefore, LPN candidate patients were recommended to the RPN series.

RPN may help overcome the technical difficulties of LPN and offers an easier transition to minimally invasive PN. ${ }^{7}$ The articulating wrist-like action achieved using the da Vinci robot and 3-dimensional visualization would offer potential advantages during a $\mathrm{PN}$. In particular, tumour excision and intracorporeal suture repair may be facilitated. The ease of tumour excision and suture repair may translate into shorter WIT and a reduction in uncontrolled bleeding after unclamping. ${ }^{27}$ Rogers and colleagues ${ }^{28}$ reported that robotic assistance could be advantageous for renal hilar tumours and demonstrated that RPN could be both safe and effective in complex renal masses. Benway and colleagues ${ }^{29}$ reported that the WIT in RPN was shorter than in LPN and involved less EBL compared to a series that examined 129 RPN and 118 LPN patients. In our series, the mean WIT of RPNs was about 20 minutes; there was no positive surgical margin and no significant decrease in renal function. This evidence suggests that RPN was safe and effective for PN.

Although several studies compared the clinical outcomes between RPN and LPN, few reports have compared OPN and RPN. One retrospective study recently compared 69 RPNs with 234 OPNs. ${ }^{10}$ The findings showed that the mean operation time and WIT were longer in the RPN group, but there were no significant differences in the postoperative
GFR. However, this series had considerable selection bias. To our knowledge, our matched cohort study represents the only single-surgeon series in which RPN outcomes were compared with a control group of OPN patients operated on by the same surgeon.

The results of our matched cohort study support the role of RPN in the management of small, radiographically enhancing renal masses. Both cohorts demonstrated excellent renal functional and perioperative outcomes. In a PN series, WIT is usually accepted as the crucial parameter for evaluating reasonable operative outcomes. ${ }^{9}$ After matching the renal tumour profile (size, location and laterality), patient age and ASA score, WIT was similar between OPN and RPN (21.18 vs. 21.86 min, $p=0.734$ ), in contrast to a previous study. ${ }^{10}$ Moreover, hospital stay and postoperative pain (as represented by the dosage of analgesics) were shorter in the RPN cohort than in the OPN cohort. This identifies RPN as a new alternative to OPN.

The primary limitation of our study was its retrospective nature. Selection bias and patient confounders were minimized by matching the RPN cohort to demographically similar OPN patients. Surgical confounders were minimized by using the outcomes of a single surgeon. Further randomized, controlled, prospective trials are needed to confirm our results.

\section{Conclusions}

The outcomes of this study support RPN as an effective and safe alternative to OPN. With the improvements in related technology, RPN might be easier and more effective than renal surgery. RPN has become a popular procedure because of its short learning curve and the translational capacity of the robotic operating platform coupled with its superior optics and flexibility. Further prospective comparative studies are necessary to confirm these encouraging findings.

Competing interests: Dr. Oh, Dr. Byun, Dr. Hong, Dr. Jeong and Dr. Lee all declare no competing financial or personal interests.

This paper has been peer-reviewed.

\section{References}

1. Robson CJ, Churchill BM, Anderson W. The results of radical nephrectomy for renal cell carcinoma. J Urol 1969;101:297-301.

2. Gill IS, Aron M, Gervais DA, et al. Clinical practice. Small renal mass. N Engl J Med 2010;362:624-34. http://dx.doi.org/10.1056/NEJMcp0910041

3. Liungberg B, Hanbury DC, Kuczyk MA, et al. Renal cell carcinoma guideline. Eur Urol 2007;51:1502-10. http://dx.doi.org/10.1016/i.eururo.2007.03.035

4. Russo $P$, Huang $W$. The medical and oncological rationale for partial nephrectomy for the treatment of T1 renal cortical tumors. Urol Clin North Am 2008;35:635-43. http://dx.doi.org/10.1016/i. ucl.2008.07.008 
5. Huang WC, Elkin EB, Levey AS, et al. Partial nephrectomy versus radical nephrectomy in patients with small renal tumors-is there a difference in mortality and cardiovascular outcomes? J Urol 2008;181:55-61. http://dx.doi.org/10.1016/i.juro.2008.09.017

6. Kaul S, Laungani R, Sarle R, et al. da Vinci-assisted robotic partial nephrectomy: Technique and results at a mean of 15 months of follow-up. Eur Urol 2008;51:186-91. http://dx.doi.org/10.1016/i. eururo.2006.06.002

7. Rogers CG, Patard JJ. Open to debate. The motion: Robotic partial nephrectomy is better than open partial nephrectomy. Eur Urol 2009;56:568-70. http://dx.doi.org/10.1016/i.eururo.2009.06.026

8. Phillips CK, Taneja SS, Stifelman MD. Robot-assisted laparoscopic partial nephrectomy: The NYU technique. J Endourol 2005;19:441-5. http://dx.doi.org/10.1089/end.2005.19.441

9. Mottrie A, De Naeyer $G$, Schatteman $P$, et al. Impact of the learning curve on perioperative outcomes in patients who underwent robotic partial nephrectomy for parenchymal renal tumours. Eur Urol 2010;58:127-32. http://dx.doi.org/10.1016/i.eururo.2010.03.045

10. Lee S, Oh J, Hong SK, et al. Open versus robot-assisted partial nephrectomy: Effect on clinical outcome. J Endourol 2011;25:1181-5. hitp://dx.doi.org/10.1089/end.2010.0670

11. Kutikov A, Uzzo RG. The R.E.N.A.L. nephrometry score: A comprehensive standardized system for quantitating renal tumor size,location and depth. J Urol 2009;182:844-53. http://dx.doi.org/10.1016/i. juro. 2009.05.035

12. Finley DS, Lee DI, Eichel L, et al. Fibrin glue-oxidized cellulose sandwich for laparoscopic wedge resection of small renal lesions. J Urol 2005;173:1477-81. http://dx.doi.org/10.1097/01. ju. $0000154165.12738 .7 f$

13. Edge SB, Compton CC. The American Joint Committee on Cancer: the 7th edition of the AICC cancer staging manual and the future of TNM. Ann Surg Oncol 2010;17:1471-4. http://dx.doi.org/10.1245/ s10434-010-0985-4

14. Baumert H, Ballaro A, Shah N, et al. Reducing warm ischaemia time during laparoscopic partial nephrectomy: A prospective comparison of two renal closure techniques. Eur Urol 2007;52:1164-9. http:// dx.doi.org/10.1016/i.eururo.2007.03.060

15. Dindo D, Demartines N, Clavien PA. Classification of surgical complications: A new proposal with evaluation in a cohort of 6336 patients and results of a survey. Ann Surg 2004;240:205-13. http://dx.doi. org/10.1097/01.sla.0000133083.54934.ae

16. Becker $F$, Siemer $S$, Humke $U$, et al. Elective nephron sparing surgery should become standard treatment for small unilateral renal cell carcinoma: Long-term survival data of 216 patients. Eur Urol 2006; $49: 308$ 13. http://dx.doi.org/10.1016/i.eururo.2005.10.020

17. Joniau $S$, Vander Eeckt K, Srirangam SJ, et al. Outcome of nephron-sparing surgery for Tlb renal cell carcinoma. BJU Int 2009;103:1344-8. http://dx.doi.org/10.1111/j.1464-410X.2008.08230.x
18. Becker $F$, Siemer $S$, Hack $M$, et al. Excellent long-term cancer control with elective nephron-sparing surgery for selected renal cell carcinomas measuring more than $4 \mathrm{~cm}$. Eur Urol 2006;49:1058-63. http://dx.doi. org/10.1016/i.eururo.2006.03.003

19. Haber GP, White WM, Crouzet $S$, et al. Robotic versus laparoscopic partial nephrectomy: Single-surgeon matched cohort study of 150 patients. Urology 2010;76:754-8. http://dx.doi.org/10.1016/i.urology.2010.03.058

20. Gill IS, Kavoussi LR, Lane BR, et al. Comparison of 1,800 laparoscopic and open partial nephrectomies for single renal tumors. J Urol 2007;178:41-6. http://dx.doi.org/10.1016/i.juro.2007.03.038

21. Nguyen MM, Gill IS. Halving ischemia time during laparoscopic partial nephrectomy. J Urol 2008; 179:62732. $\mathrm{http}: / /$ dx.doi.org/10.1016/i.juro.2007.09.086

22. Lane BR, Gill IS. 5-Year outcomes of laparoscopic partial nephrectomy. J Urol 2007;177:70-4. http:// dx.doi.org/10.1016/i.juro.2006.08.093

23. Allaf ME, Bhayani SB, Rogers C, et al. Laparoscopic partial nephrectomy: Evaluation of long-term oncological outcome. J Urol 2004;172:871-3. http://dx.doi.org/10.1097/01.ju.0000134292.36152.fa

24. Sukumar S, Rogers CG. Robot-assisted partial nephrectomy. J Endourol 201 1;25:151-7. http://dx.doi. org/10.1089/end.2010.0672

25. Gill IS, Abreu SC, Desai MM, et al. Laparoscopic ice slush renal hypothermia for partial nephrectomy: The initial experience. J Urol 2003;170:52-6. http://dx.doi.org/10.1097/01.ju.0000072332.02529.10

26. Webster TM, Moeckel GW, Herrell SD. Second prize: Simple method for achieving renal parenchymal hypothermia for pure laparoscopic partial nephrectomy. J Endourol 2005;19:1075-81. http://dx.doi. org/10.1089/end.2005.19.1075

27. DeLong JM, Shapiro 0, Moinzadeh A. Comparison of laparoscopic versus robotic assisted partial nephrectomy: One surgeon's initial experience. Can J Urol 2010;17:5207-12.

28. Rogers $(G$, Singh A, Blatt AM, et al. Robotic partial nephrectomy for complex renal tumors: surgical technique. Eur Urol 2008;53:514-21. http://dx.doi.org/10.1016/i.eururo.2007.09.047

29. Benway BM, Bhayani SB, Rogers (G, et al. Robot assisted partial nephrectomy versus laparoscopic partial nephrectomy for renal tumors: A multi-institutional analysis of perioperative outcomes. J Urol 2009;182:866-72. http://dx.doi.org/10.1016/i.juro.2009.05.037

Correspondence: Dr. Seoksoo Byun, Department of Urology, Seoul National University Bundang Hospital, Seongnam, Korea; ssbyun@snubh.org 